Supporting Information

Direct Intra-nuclear Anticancer Drug Delivery via Polydimethylsiloxane Nanoparticles: In Vitro and In Vivo

\title{
Xenograft Studies
}

Gargi Mishra $^{1}$, Souryadeep Bhattacharyya ${ }^{1}$, Vipul Bhatia ${ }^{3}$, Bushra Ateeq ${ }^{3}$, Ashutosh Sharma $^{1 \#}$ and Sri Sivakumar ${ }^{2 \#}$

${ }^{1}$ Department of Chemical Engineering, Centre for Environmental Science \& Engineering, Thematic Unit of Excellence in Soft Nanofabrication, Indian Institute of Technology Kanpur, Kanpur-208016, U.P., India

${ }^{2}$ Material Science Programme, Indian Institute of Technology Kanpur, Kanpur-208016, U.P., India

${ }^{3}$ Department of Biological Sciences \& Bioengineering, Indian Institute of Technology Kanpur, Kanpur-208016, U.P., India

*E-mail: ashutos@iitk.ac.in, srisiva@,iitk.ac.in 
Table S1: Details of amount of Dox loaded on PDMS-Dox samples for MTT of HeLa, A498 and HepG2 cells

\begin{tabular}{|l|l|l|}
\hline $\begin{array}{c}\text { Sample of PDMS-Dox } \\
\text { (for HeLa, A498 and } \\
\text { HepG2) }\end{array}$ & \multicolumn{1}{|c|}{$\begin{array}{c}\text { PDMS } \\
\text { concentration } \\
(\boldsymbol{\mu g} / \mathbf{m l})\end{array}$} & $\begin{array}{c}\text { Dox Concentration } \\
\text { loaded on particles } \\
(\boldsymbol{\mu g} / \mathbf{m l})(\boldsymbol{\mu} \mathbf{M})\end{array}$ \\
\hline 1. Control & 0 & 0 \\
\hline 2. $\mathrm{P}_{10}$ & 10 & $0.06(103 \mathrm{nM})$ \\
\hline $3 . \mathrm{P}_{25}$ & 25 & $0.14(241 \mathrm{nM})$ \\
\hline $4 . \mathrm{P}_{50}$ & 50 & $0.29(500 \mathrm{nM})$ \\
\hline $5 . \mathrm{P}_{100}$ & 100 & $0.56(965 \mathrm{nM})$ \\
\hline $6 . \mathrm{P}_{125}$ & 125 & $0.75(1288 \mathrm{nM})$ \\
\hline
\end{tabular}

P stands for PDMS-Dox NPs concentration. Loading percentage of Dox on PDMS-Dox NPs is $6 \%(\mathrm{w} / \mathrm{w})$.

Table S2: Details of amount of Dox loaded on PDMS-Dox samples for MTT of PC-3 cells

\begin{tabular}{|l|l|l|}
\hline $\begin{array}{c}\text { Sample of PDMS-Dox } \\
(\text { for PC-3) }\end{array}$ & $\begin{array}{c}\text { PDMS concentration } \\
(\boldsymbol{\mu} / \mathbf{m l})\end{array}$ & $\begin{array}{c}\text { Dox Concentration } \\
\text { loaded on particles } \\
(\boldsymbol{\mu g} / \mathbf{m l})(\boldsymbol{\mu M})\end{array}$ \\
\hline 1. Control & 0 & 0 \\
\hline 2. $\mathrm{P}_{5}$ & 5 & $0.425(733 \mathrm{nM})$ \\
\hline 3. $\mathrm{P}_{10}$ & 10 & $0.85(1.46 \mu \mathrm{M})$ \\
\hline 4. $\mathrm{P}_{25}$ & 25 & $2.125(3.66 \mu \mathrm{M})$ \\
\hline 5. $\mathrm{P}_{50}$ & 50 & $4.25(7.3 \mu \mathrm{M})$ \\
\hline 6. $\mathrm{P}_{100}$ & 100 & $8.5(14.6 \mu \mathrm{M})$ \\
\hline
\end{tabular}

P stands for PDMS-Dox NPs concentration. Loading percentage of Dox on PDMS-Dox NPs is $8.5 \%(\mathrm{w} / \mathrm{w})$. 


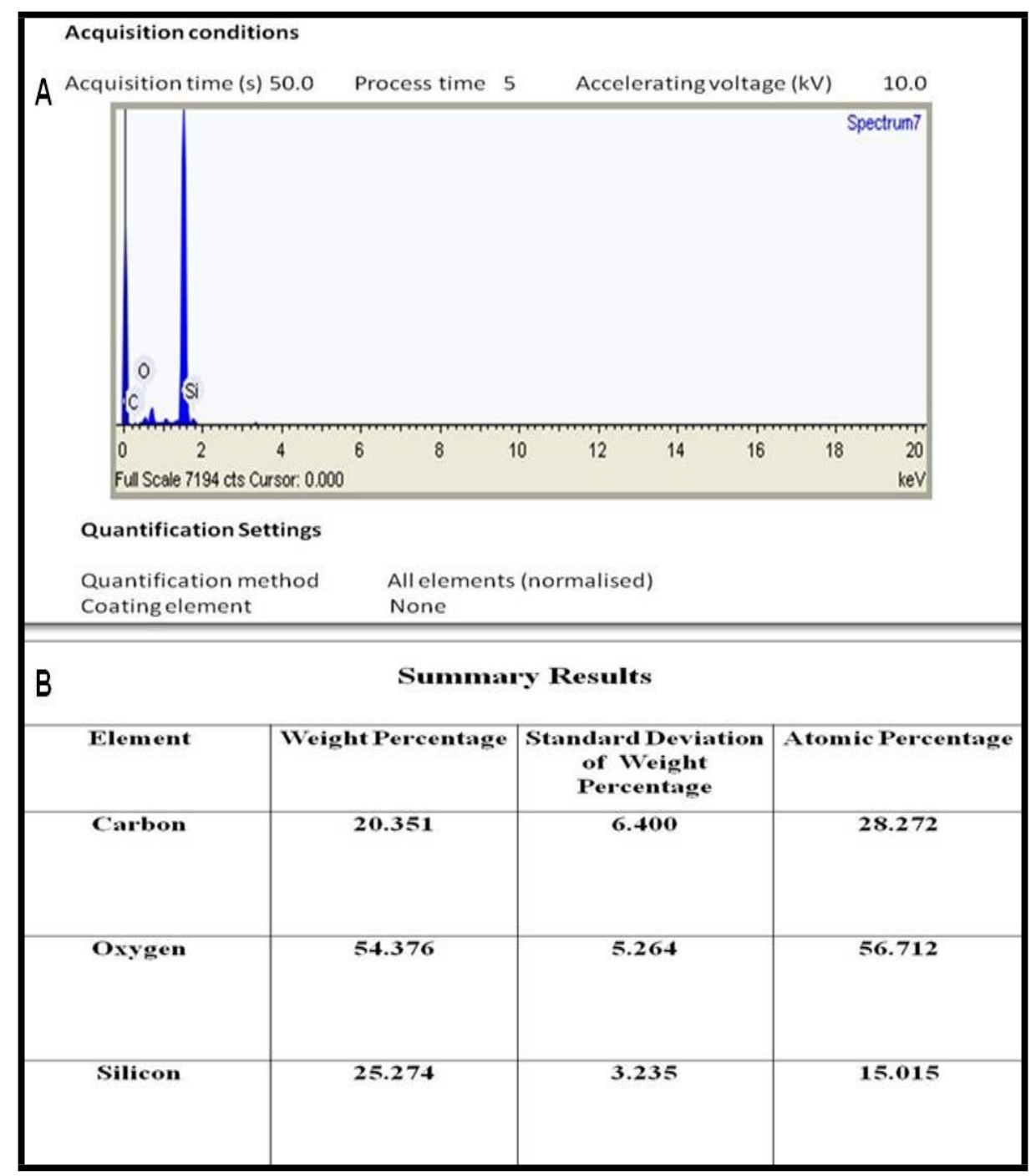

Figure S1. (a) EDAX of PDMS nanoparticles, (b) Elemental composition of PDMS nanoparticles 


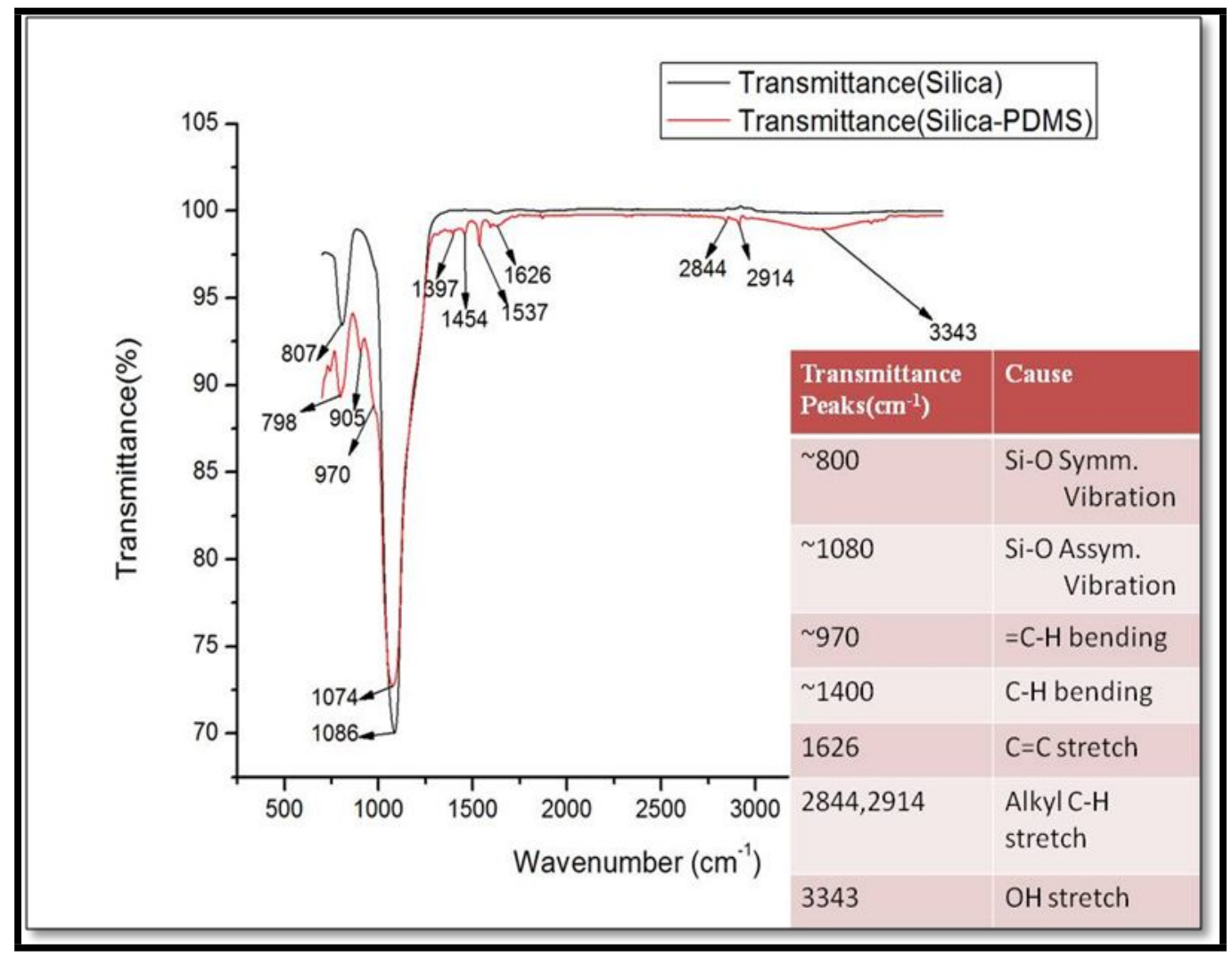

Figure S2. FTIR spectroscopy of PDMS nanoparticles 


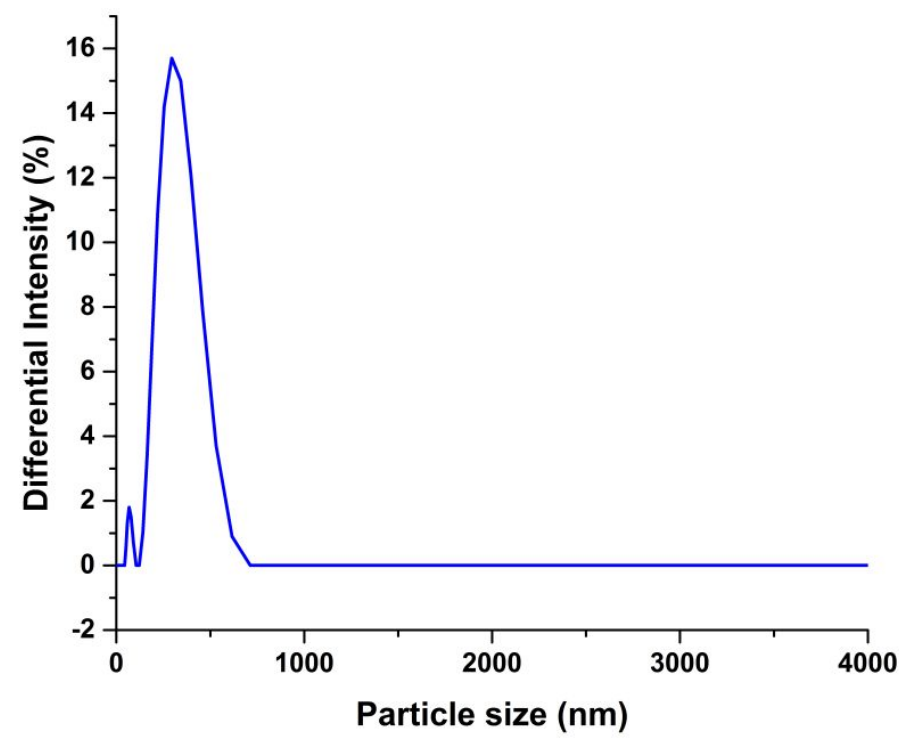

Figure S3. DLS of bare PDMS nanoparticles possessing the average size $296 \mathrm{~nm}$ 


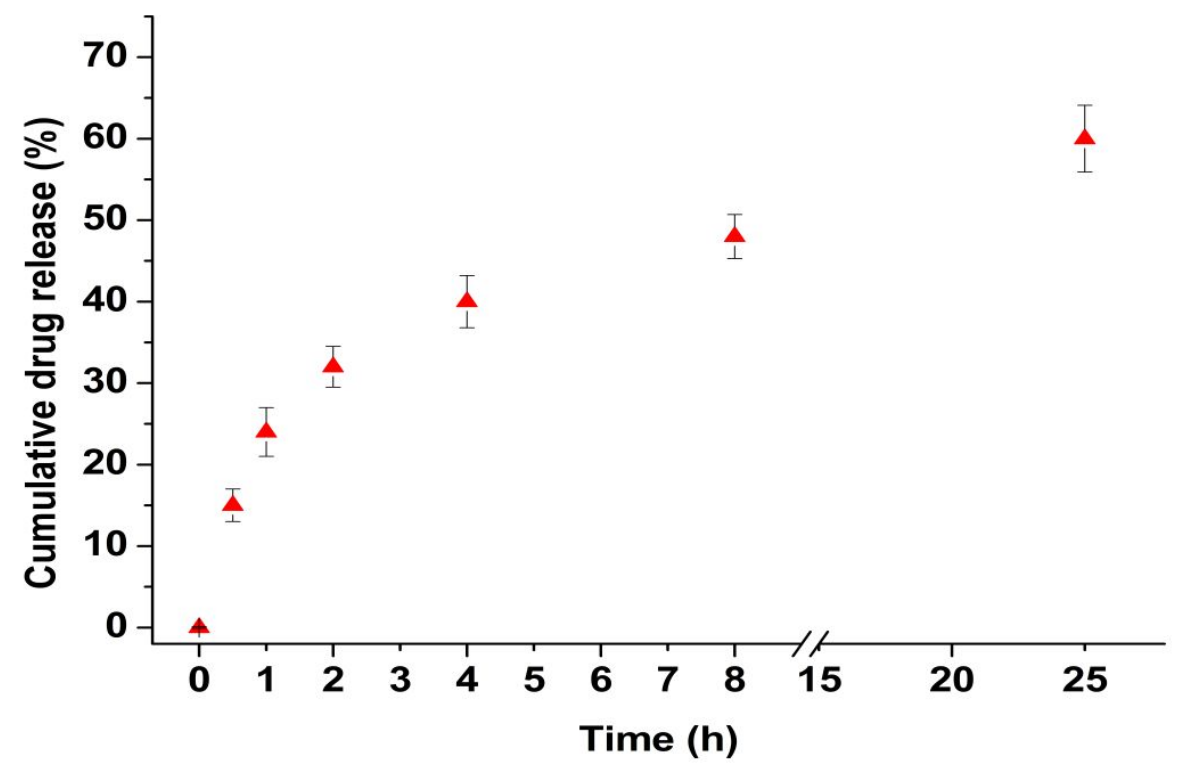

Figure S4. In vitro drug release profile of dox loaded PDMS nanoparticles in PBS (pH 7.4) at $25{ }^{\circ} \mathrm{C}$ for 25 hours. The fluorescence of released dox was measured in the PBS buffer at 484 $\mathrm{nm}$ and the cumulative drug release was plotted against different time intervals. 


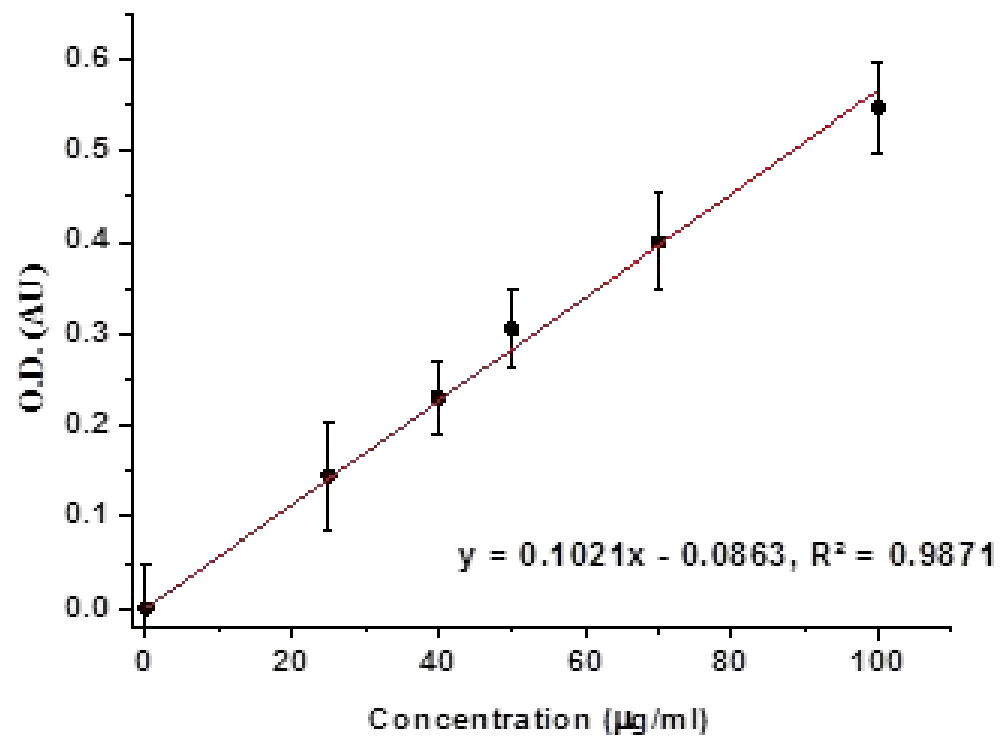

Figure S5. Calibration curve of Doxorubicin hydrochloride in PBS recorded at $37^{\circ} \mathrm{C}$. Absorbance was taken at $484 \mathrm{~nm}$. 


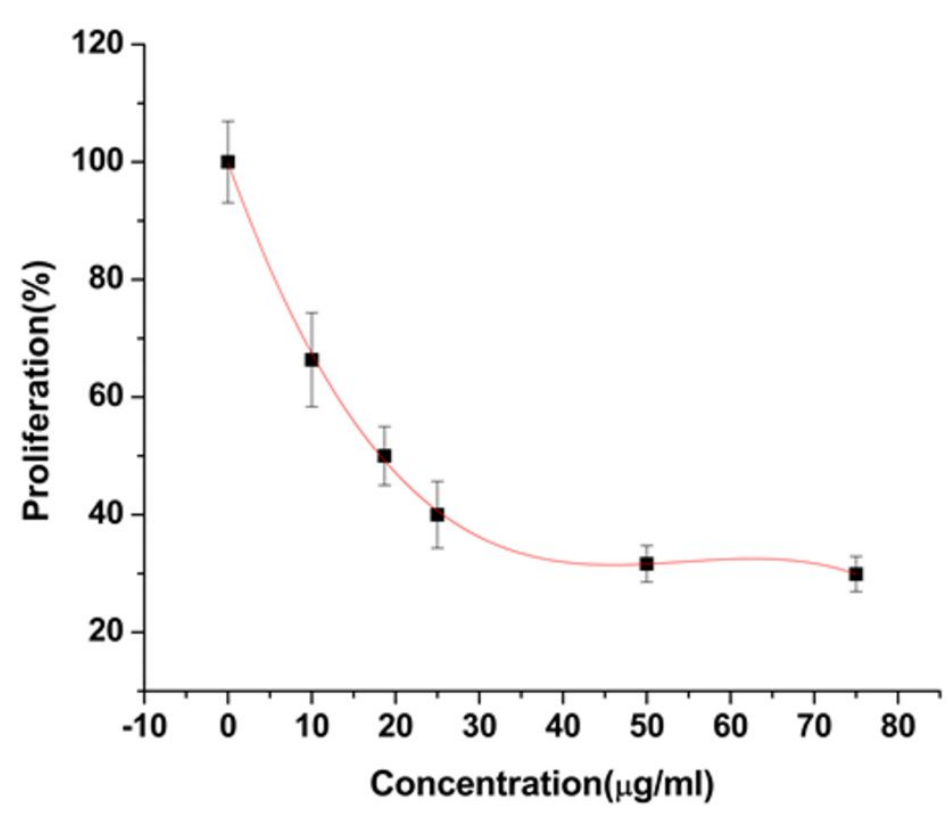

Figure S6. IC50 curve of PDMS-dox nanoparticles for A498 cells, IC50 value for PDMS-dox conjugate is $0.18 \mu \mathrm{M}$ and free dox is $0.24 \mu \mathrm{M}$. 


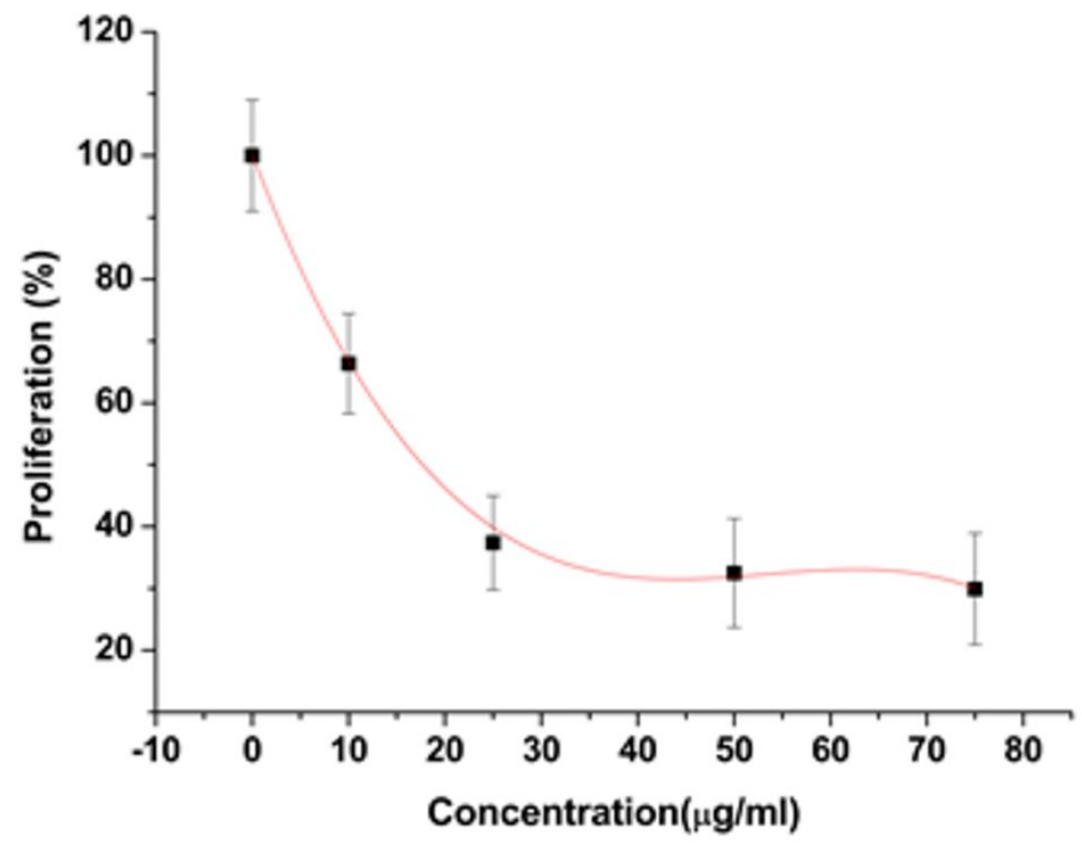

Figure S7. The IC50 curve of PDMS-dox nanoparticles for HeLa cells, IC50 value for PDMS-dox NPs conjugate is $0.18 \mu \mathrm{M}$ and free dox is $1.12 \mu \mathrm{M}$. 


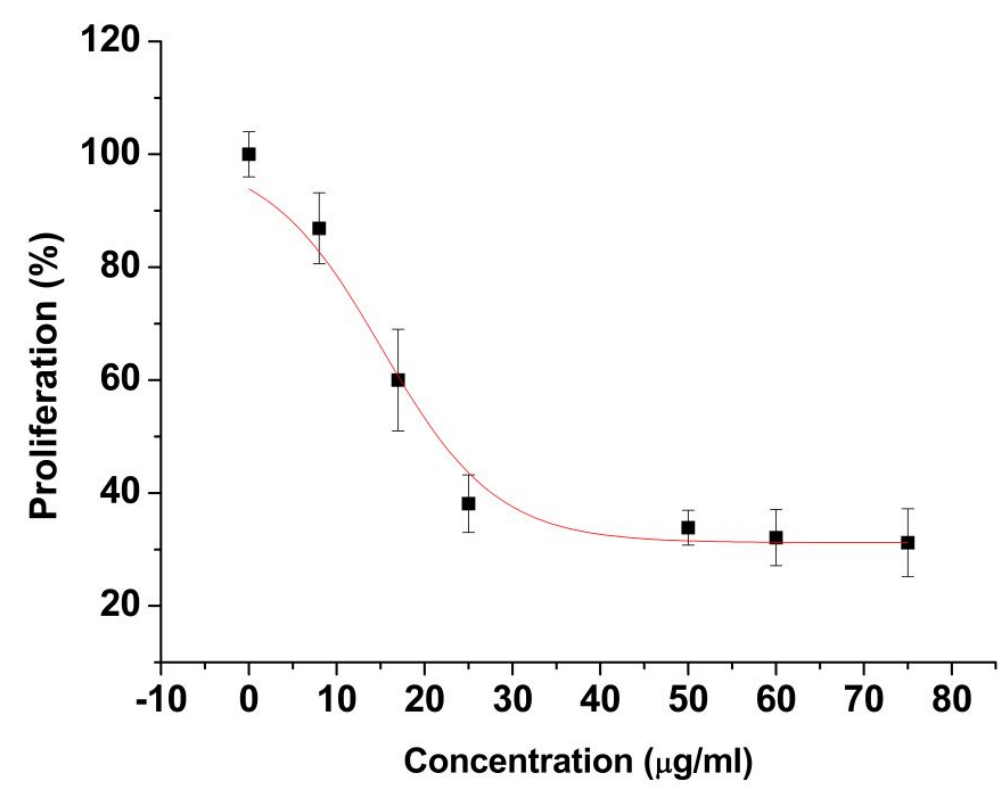

Figure S8. IC50 curve of PDMS-dox nanoparticles for HepG2 cells, IC50 value for PDMSdox is $0.2 \mu \mathrm{M}$ and free dox is $0.72 \mu \mathrm{M}$ 


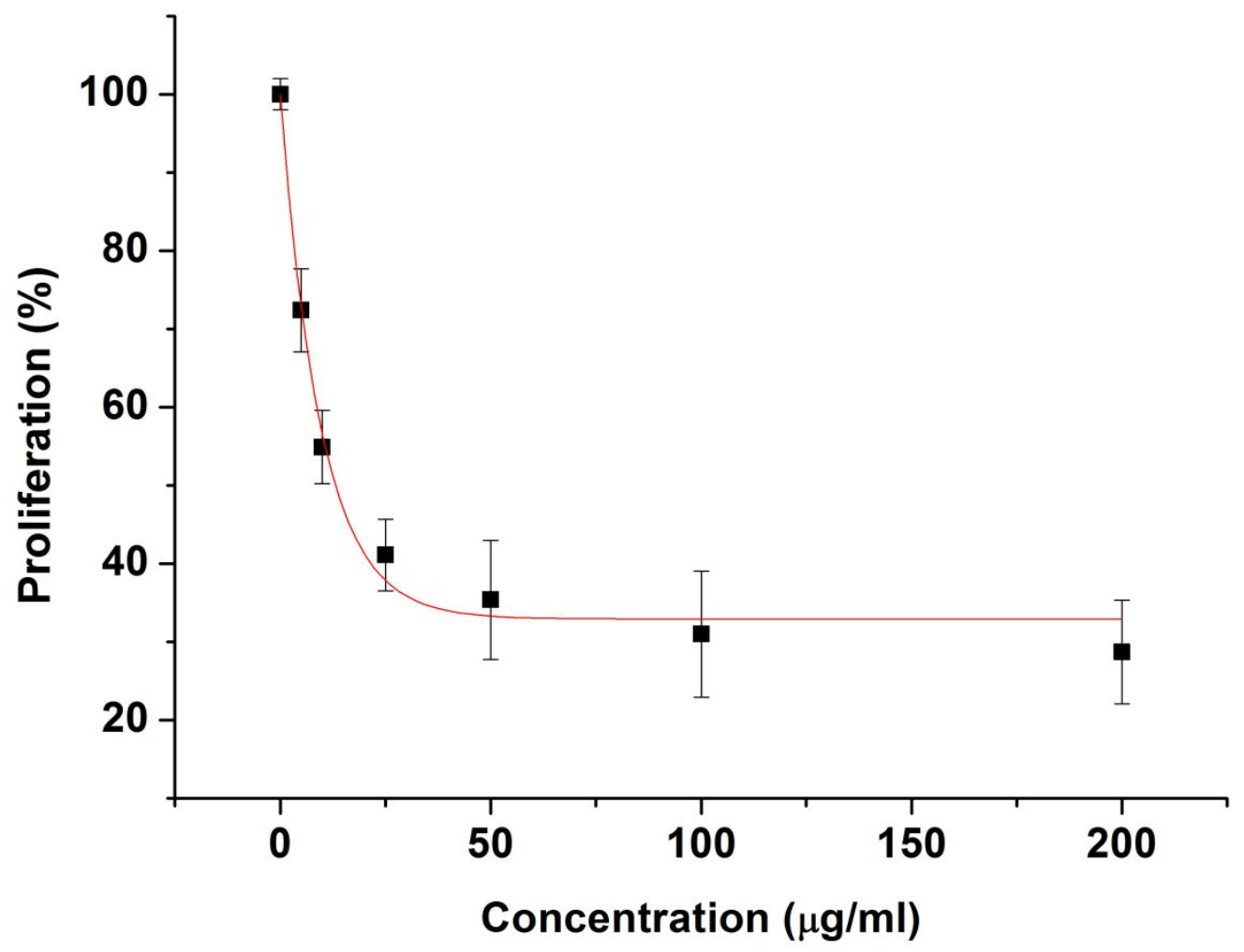

Figure S9. IC50 curve of PDMS-dox nanoparticles for PC-3 cells, PDMS-Dox IC 50 value is $1.14 \mu \mathrm{M}$ and free dox IC 50 value is $2.47 \mu \mathrm{M}$.

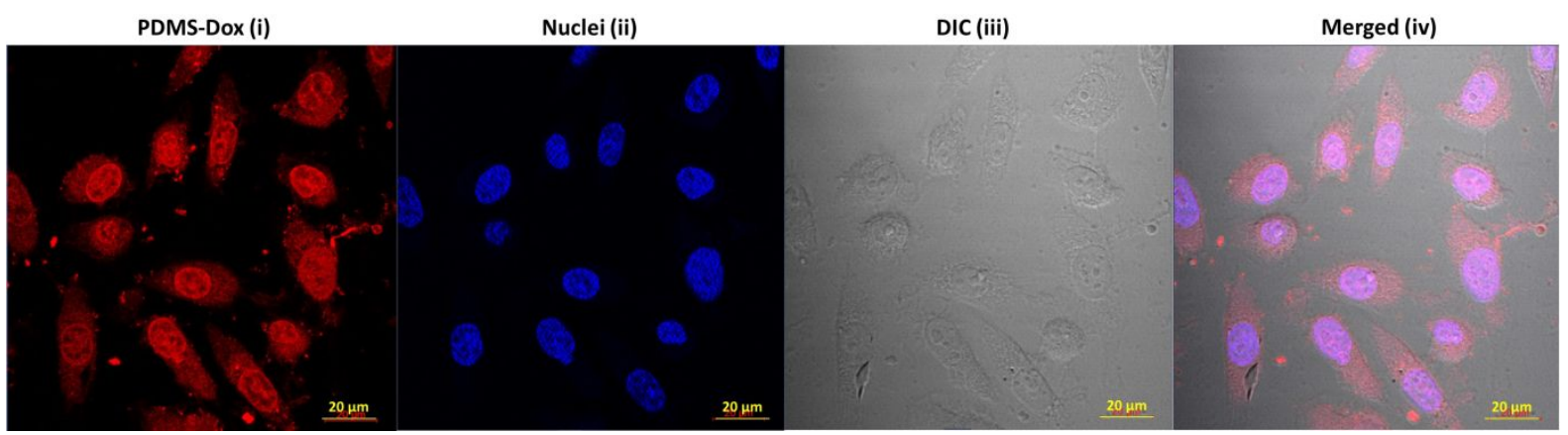

Figure S10. Nanoparticle internalization of PDMS-Dox NPs in HeLa cells; (i) PDMS-Dox, (ii) nuclei-Hoechst, (iii) DIC image and (iv) merged image; scale bar represents $20 \mu \mathrm{m}$. 

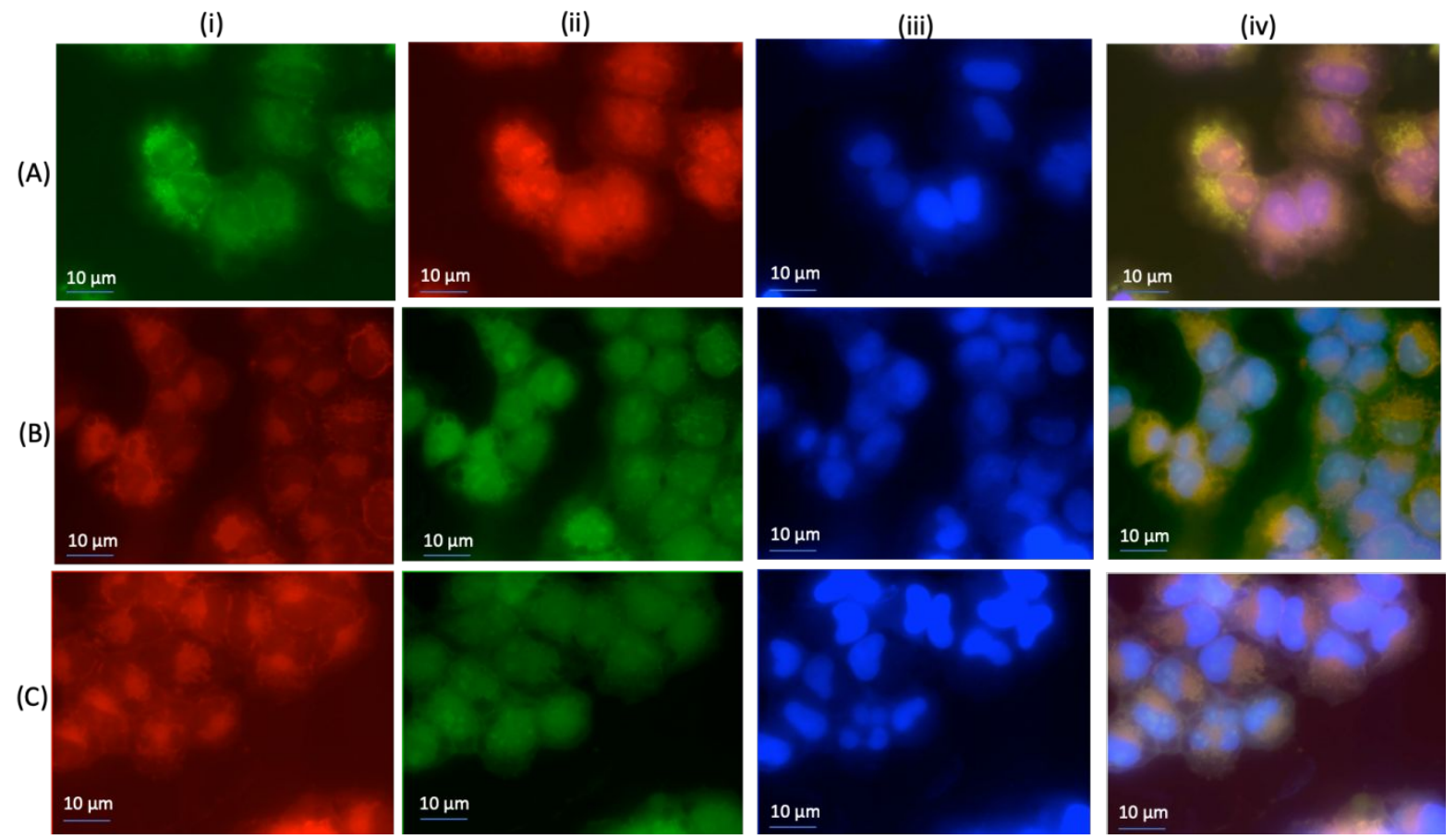

Figure S11: Free drug and dyes internalization in HeLa cells; (A) FITC internalization: (i) free FITC, (ii) cells stained with deep membrane red dye, (iii) nuclei stained with Hoechst and (iv) merged image; (B) RITC internalization: (i) free RITC, (ii) cells stained with FITC-phalloidin (iii) nuclei stained with Hoechst and (iv) merged image and (C) Dox internalization: (i) free Dox, (ii) cells stained with FITC-phalloidin, (iii) nuclei stained with Hoechst and (iv) merged image 

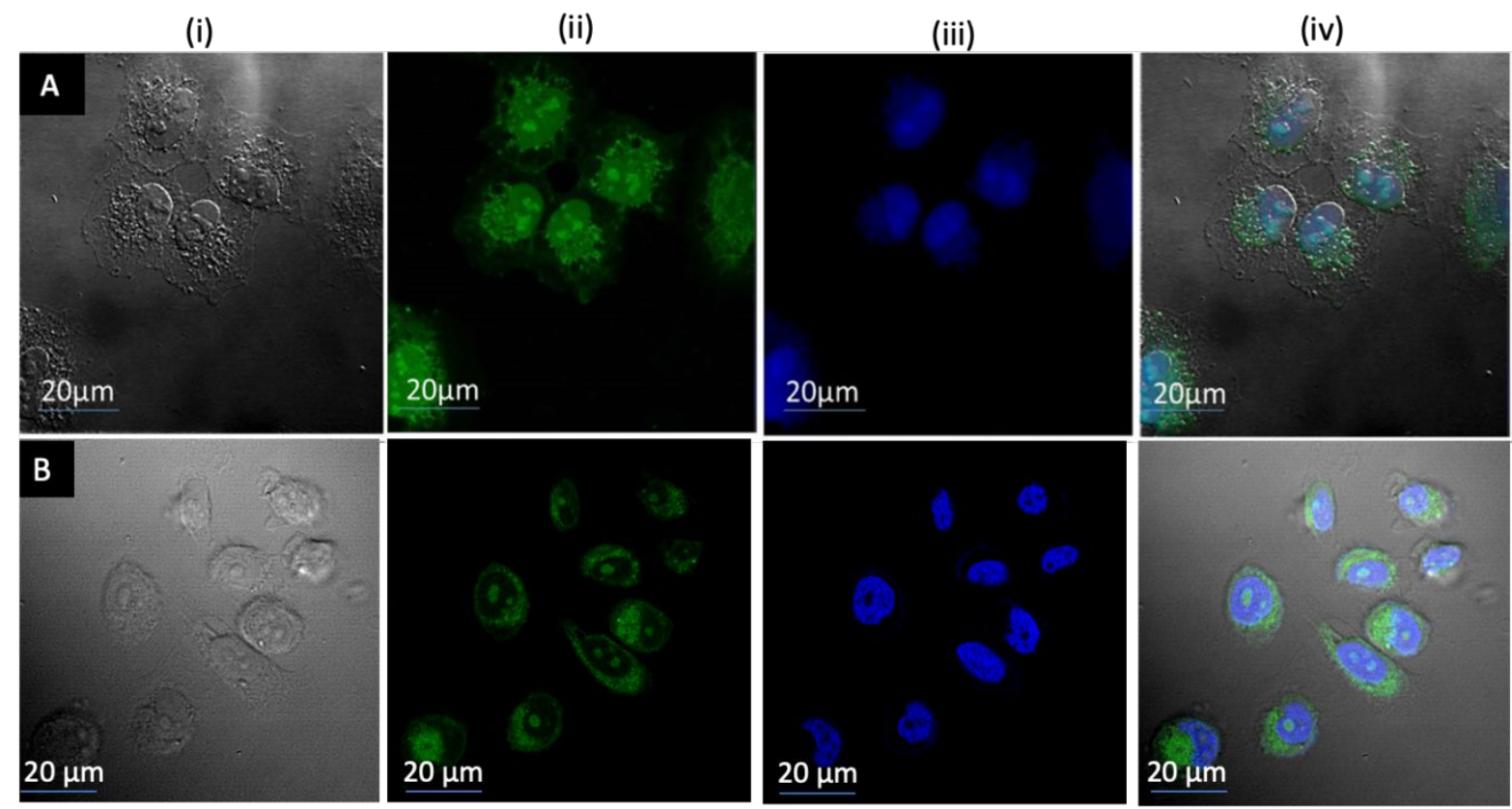

Figure S12. Confocal microscopic images of PDMS-FITC NPs internalized in (A) HepG2 and (B) A498 cells; (i) cells (DIC image), (ii) PDMS-FITC NPs (green), (iii) nuclei stained with Hoechst (blue) and (iv) merged image 